\title{
IMPACT OF USING ADDITIVES ON QUALITY \\ OF AGRICULTURAL BIOMASS PELLETS
}

\author{
Iuliana Gageanu ${ }^{1}$, Dan Cujbescu ${ }^{1}$, Catalin Persu ${ }^{1}$, Gheorghe Voicu ${ }^{2}$ \\ ${ }^{1}$ National Institute of Research-Development for Machines and Installations Designed to Agriculture \\ and Food Industry, Romania; ${ }^{2}$ University Politehnica of Bucharest, Romania \\ iulia.gageanu@gmail.com,dcujbescu@yahoo.com, persucatalin@yahoo.com, \\ ghvoicu_2005@yahoo.com
}

\begin{abstract}
The benefits of biofuels, compared to traditional fuels, target higher energy security, lower environmental impact, financial savings and socio-economic benefits related to the rural sector. The concept of sustainable development embodies the idea of inter-connectivity and balance between economic, social and environmental concerns. Materials with lignocellulosic structure (wood, straws, stalks, etc.) represent important renewable energy resources. Their main disadvantage consists in the fact that they have very low bulk density, which leads to difficulties in the process of handling, transport, storage, respectively increased production costs. Besides this, high variations of moisture in the material can generate difficulties in the operation and adjustment of processes within the installations where they are used. These drawbacks can be improved by drying and densifying the material at very high pressures, thus obtaining solid biofuels with a uniform structure, such as pellets. Quality attributes of pellets can be influenced by using different additives and binders in the production process. Changes in the recipes used can lead to increased yields and also to improved product quality (in terms of density, inferior calorific value, durability, etc.). The paper presents a series of experimental researches conducted on pellets obtained from agricultural biomass, with and without using additives in the recipes, determining the influence of these additives on the quality of pellets used for energy purposes.
\end{abstract}

Keywords: agricultural biomass, pellets, additives, inferior calorific value.

\section{Introduction}

The rapid depletion of fossil fuels combined with the severe climate and environmental changes that occurred in the last years have led to the necessity of finding new forms of energy that are both environmentally friendly, but also efficient.

One of the most abundant and accessible forms of energy is represented by biomass. Biomass has the advantages that it has characteristics very similar to those of fossil fuels, it can be used in the same purposes, and can be introduced in the same systems for energy production [1].

Agricultural residues are an abundant and cheap source of energy from renewable sources. They are the most abundant (in terms of mass) biomass raw material in the world. Due to the availability of this enormous amount of agricultural residue, they have recently been considered as a potential raw material for biofuel production. However, biomass from wheat straw and other crops has the disadvantage of having high porosity and low bulk density. Straw densification has big importance for better handling, transport and storage. Densification can increase the uniformity of physical properties leading to the production of denser, more uniform, clean and energy-stable pellets.

The pelleting process is one of the best ways to densify agricultural residues. It requires that the raw material - biomass is grinded to small sizes, homogenized and forced to pass through the small orifices of a special die, thus forming small granules - pellets. Pelletization of agricultural biomass cereal straws, stems of various materials, leaves, etc. represents a good option for farmers to safely manage these residues, but also to ensure themselves a part of the necessary energy for their daily activities.

The latest challenges in the sector of biomass pelleting are to enhance the quality attributes of the products obtained in terms of better handling, longer storage time, better combustion, etc. An answer to this challenge was found by introducing various additives in pelleting recipes to improve quality [26]. The paper presents a series of experimental researches conducted on pellets obtained with and without additives to determine the influence of additives on the quality of final products.

\section{Materials and methods}

The pellets analysed were all obtained in the same conditions, using the same pelleting installation (comprised of biomass grinder, biomass drier, homogenizing equipment, feeding bunker, ring die pelleting equipment, cooling equipment). 
The recipes were chosen so as to have the possibility to make a comparison between the pellets obtained without additives and the ones obtained using additives. The pellets produced with additives were obtained using materials from the same batches as those without additives, therefore it can be considered that the changes in quality can be attributed only to the use of additional materials in the composition of pellets. Pellets were obtained using biomass residues represented by wheat straws, rapeseed stalks, corn stalks, corn cobs. The materials came from farmers situated in Prahova County / Romania.

The recipes obtained from agricultural biomass materials with / without additives, used to obtain pellets, are presented in Table 1.

Table 1

\section{Recipes used for pelleting}

\begin{tabular}{|c|l|c|}
\hline Sample & \multicolumn{1}{|c|}{ Biomass materials } & Additives \\
\hline 1 & Wheat straws 100\% & - \\
\hline 2 & Rapeseed stalks 100\% & - \\
\hline 3 & Corn stalks 100\% & - \\
\hline 4 & Wheat straws 50\% + Rapeseed stalks 50\% & - \\
\hline 5 & Wheat straws 95\% & Paraffin 5\% \\
\hline 6 & Wheat straws 93.5\% & $\begin{array}{c}\text { Paraffin 1.5\% + Corn starch } \\
5 \%\end{array}$ \\
\hline 7 & $\begin{array}{l}\text { Wheat straws 55\% + Rapeseed stalks 30\% + Corn stalks } \\
10 \%\end{array}$ & Dolomite 5\% \\
\hline 8 & $\begin{array}{l}\text { Wheat straws 55\% + Rapeseed stalks 30\% + Corn cobs } \\
10 \%\end{array}$ & Dolomite 5\% \\
\hline
\end{tabular}

After the pellets were obtained, the following characteristics were verified:

- Overall aspect (pellets were visually analysed to determine the state of their surface, the formation of dust, the occurrence of cracks or pellet loosening after existing the die orifice);

- Moisture content $M_{c}(\%)$ was determined on a wet basis, according to the method described in the standard ISO 18134-1:2015, Solid biofuels - Determination of moisture content - Oven dry method - Part 1: Total moisture - Reference method [7].

- Bulk density $B D_{p}\left(\mathrm{~kg} \cdot \mathrm{m}^{-3}\right)$ was determined using a cylinder with known volume, and a precision scale, according to the method described in the standard ISO 17828:2015 - Solid biofuels - Determination of bulk density [8].

- Single pellet density $S D_{p}\left(\mathrm{~kg} \cdot \mathrm{m}^{-3}\right)$ was calculated using the pycnometer, determining the volume displaced by introducing the pellet in distilled water and calculating the density using the formula:

$$
S D_{p}=\frac{m_{1}}{\left(m_{2}+m_{1}-m_{3}\right) \times d_{w}}
$$

where $m_{1}$ - mass of the pellet, $\mathrm{kg}$;

$m_{2}$ - mass of pycnometer filled with distilled water, $\mathrm{kg}$;

$m_{3}$ - mass of pycnometer plus distilled water with the pellet, $\mathrm{kg}$;

$d_{w}$ - water density at working temperature, $\mathrm{kg} \cdot \mathrm{m}^{-3}$.

- Inferior calorific value $Q_{i}\left(\mathrm{MJ} \cdot \mathrm{kg}^{-1}\right)$ was determined by combusting the pellets in a calorimeter, according to the method described in the standard EN 14918:2010 - Solid biofuels. Determination of calorific value [9]. All pellet samples subjected to calorific value analysis were previosly dried in the oven to eliminate moisture.

- Ash content $A_{d}(\%)$ was determined by introducing the pellet samples in the calcination furnace at $550{ }^{\circ} \mathrm{C}$, according to the method described in the standard ISO 18122:2015 - Solid biofuels. Determination of ash content [10]. The results were calculated using the relation: 


$$
A_{d}=\frac{\left(m_{3}-m_{1}\right)}{\left(m_{2}-m_{1}\right)} \times 100 \times \frac{100}{100-M_{c}},
$$

where $A_{d}$-ash content on dry basis;

$m_{1}$ - mass of the empty crucible, $\mathrm{g}$;

$m_{2}$ - mass of the crucible with the sample for analysis, $\mathrm{g}$;

$m_{3}$ - mass of the crucible with the ash after heating, g;

$M_{c}$ - moisture content of the samples for analysis, $\%$.

- Volatile matter content $V_{d}(\%)$ was determined by introducing the pellet samples in the calcination furnace at $900{ }^{\circ} \mathrm{C}$, according to the method described in the standard ISO 18123:2015 - Solid biofuels - Determination of the content of volatile matter [11]. The results were calculated using the formula:

$$
V_{d}=\left(\frac{100\left(m_{2}-m_{3}\right)}{m_{2}-m_{3}}-M_{c}\right) \times\left(\frac{100}{100-M_{c}}\right),
$$

where $m_{1}-$ mass of the empty crucible with lid, g;

$m_{2}$ - mass of the crucible and lid plus the sample for analysis, before heating, g;

$m_{3}$ - mass of the crucible and lid plus the remaining content after heating, g;

$M_{c}$ - moisture content of the analysed samples, $\%$.
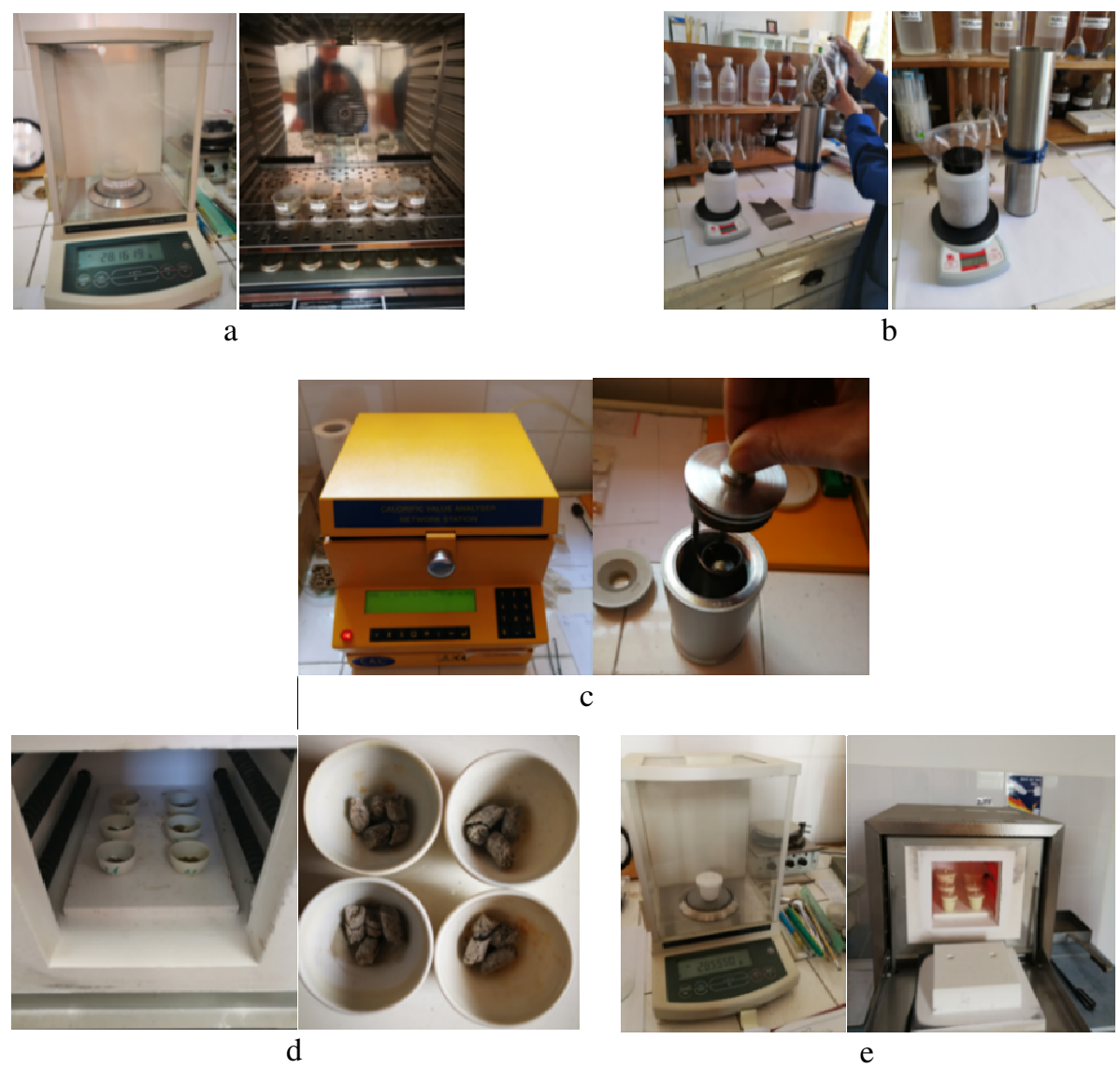

Fig. 1. Aspects during the experiments: $a$ - determination of moisture content; $b$ - determiantion of bulk density; c - determination of inferiour calorific value; $d$ - determination of ash content; $\mathrm{e}$ - determination of volatile matter content

For each sample, the number of repetitions was chosen according to the method described in the standards used, ranging from two to three repetitions. The data shown in the result tables represent the average between those repetitions. 
The equipment used for conducting the tests for analysing the pellets is presented in Table 2.

Equipment used for determinations

Table 2

\begin{tabular}{|l|c|}
\hline \multicolumn{1}{|c|}{ Equipment/type } & $\begin{array}{c}\text { Measure domain / } \\
\text { division }\end{array}$ \\
\hline Precision weighing scales /AW 220 M, with self-calibration (Shimadzu - Japan) & $0 \div 200 \mathrm{~g} / 0.1 \mathrm{mg}$ \\
\hline Furnace with temperature adjustment / -UFE 500 (Memmert - Germany) & $0 \div 260{ }^{\circ} \mathrm{C} / 1^{\circ} \mathrm{C}$ \\
\hline Calorimeter /CAL 2k (DDS Calorimeters - South Africa) & $0.001 \mathrm{MJ} \cdot \mathrm{kg}^{-1}$ \\
\hline Calcination oven, with P 320 controller (Naberterm - Germany) & $0 \div 1400{ }^{\circ} \mathrm{C} / 10^{\circ} \mathrm{C}$ \\
\hline
\end{tabular}

\section{Results and discussion}

The overall aspect of the pellets obtained is shown in Figure 2.

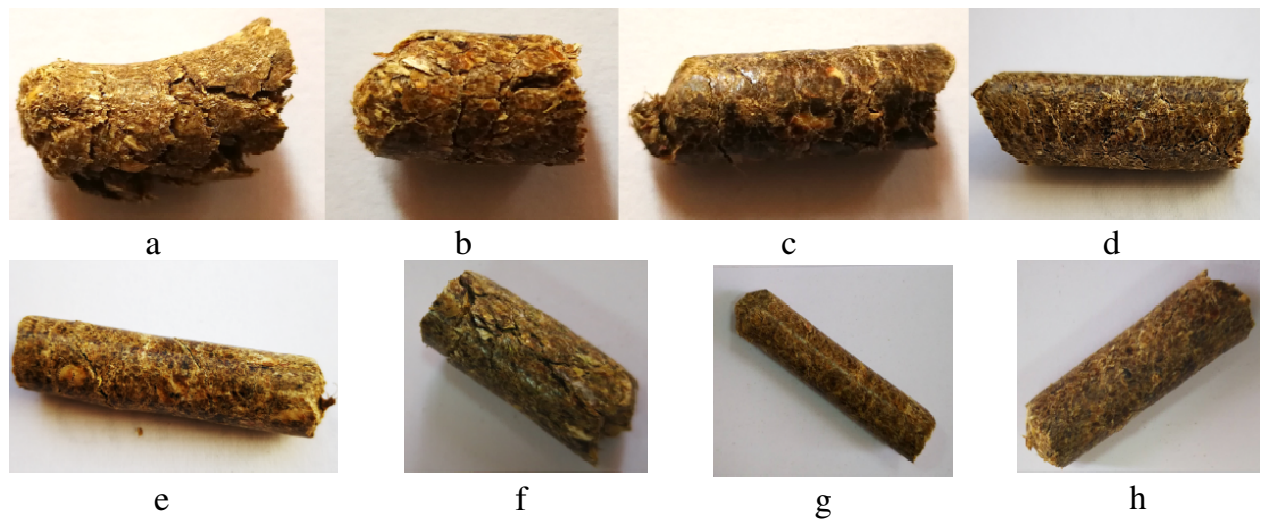

Fig. 2. Overall aspect of pellets obtained: $a$ - wheat straws; $b$ - rapeseed stalks; $c$ - corn stalks; $\mathrm{d}$ - wheat straws + rapeseed stalks; $\mathrm{e}-$ wheat straws + paraffin; $\mathrm{f}-$ wheat straws + paraffin + corn starch; $\mathrm{g}-$ wheat straws + rapeseed stalks + corn stalks + dolomite; $\mathrm{h}-$ wheat straws + rapeseed stalks + corn cobs

From the visual analysis of pellets, it was found that the addition of paraffin, corn starch and dolomite, as well as the combination between the materials had a beneficial effect on the overall aspect of the pellets. They are longer, have smoother surface and maintain their shape better than the pellet obtained without additives. The results of determinations regarding the moisture content, bulk density and single pellet density are presented in Table 3.

Moisture content, bulk density and single pellet density of analysed pellets

Table 3

\begin{tabular}{|c|l|c|c|c|}
\hline Sample & \multicolumn{1}{|c|}{ Sample composition } & $\begin{array}{c}\text { Moisture } \\
\text { content, } \\
\%\end{array}$ & $\begin{array}{c}\text { Bulk } \\
\mathbf{d e n s i t y} \\
\mathbf{k g} \cdot \mathbf{m}^{-3}\end{array}$ & $\begin{array}{c}\text { Single pellet } \\
\mathbf{d e n s i t y , ~} \\
\mathbf{k g} \cdot \mathbf{m}^{-3}\end{array}$ \\
\hline 1 & Wheat straws 100\% & 8.25 & 544.53 & 970.12 \\
\hline 2 & Rapeseed stalks 100\% & 11.65 & 495.17 & 897.72 \\
\hline 3 & Corn stalks 100\% & 11.44 & 607.32 & 1343.81 \\
\hline 4 & Wheat straws 50\% + Rapeseed stalks 50\% & 10.19 & 558.66 & 1019.63 \\
\hline 5 & Wheat straws 95\% + Paraffin 5\% & 9.25 & 591.50 & 1175.86 \\
\hline 6 & Wheat straws 93.5\% + Paraffin 1.5\% + Corn starch 5\% & 7.48 & 637.78 & 1212.78 \\
\hline 7 & $\begin{array}{l}\text { Wheat straws 55\% + Rapeseed stalks 30\% + Corn } \\
\text { stalks 10\% + Dolomite 5\% }\end{array}$ & 9.14 & 622.71 & 1118.81 \\
\hline 8 & $\begin{array}{l}\text { Wheat straws 55 \% + Rapeseed stalks 30\% + Corn } \\
\text { cobs 10\% + Dolomite 5\% }\end{array}$ & 7.70 & 637.90 & 1090.66 \\
\hline
\end{tabular}

The results regarding the inferior calorific value, ash content and volatile matter content are presented in Table 4.

Figure 3 presents the evolution of the bulk density and single pellet density in the case of pellets obtained using wheat straws as the main biomass material. We can see that sample 3 (corn stalks 
$100 \%)$ registered the largest difference between the bulk density and single pellet density, mainly due to the fact that corn stalk pellets had the largest average length and occupied a large volume. In the case of the other samples the difference is normal.

Table 4

Inferior calorific value, ash content and volatile matter content of analysed pellets

\begin{tabular}{|c|c|c|c|c|}
\hline Sample & Sample composition & $\begin{array}{c}\text { Inferior } \\
\text { calorific value, } \\
\mathrm{MJ} \cdot \mathrm{kg}^{-1}\end{array}$ & $\begin{array}{c}\text { Ash } \\
\text { content, } \\
\%\end{array}$ & $\begin{array}{c}\text { Volatile } \\
\text { matter } \\
\text { content, \% }\end{array}$ \\
\hline 1 & Wheat straws $100 \%$ & 16.603 & 8.03 & 76.92 \\
\hline 2 & Rapeseed stalks $100 \%$ & 15.827 & 7.35 & 80.93 \\
\hline 3 & Corn stalks $100 \%$ & 13.924 & 14.09 & 73.75 \\
\hline 4 & Wheat straws $50 \%+$ Rapeseed stalks $50 \%$ & 16.150 & 7.66 & 76.99 \\
\hline 5 & Wheat straws $95 \%$ + Paraffin $5 \%$ & 15.815 & 6.41 & 77.36 \\
\hline 6 & $\begin{array}{l}\text { Wheat straws } 93.5 \%+\text { Paraffin } 1.5 \%+ \\
\text { Corn starch } 5 \%\end{array}$ & 16.442 & 6.98 & 76.96 \\
\hline 7 & $\begin{array}{l}\text { Wheat straws } 55 \%+\text { Rapeseed stalks } 30 \% \\
+ \text { Corn stalks } 10 \%+\text { Dolomite } 5 \%\end{array}$ & 16.847 & 10.35 & 73.41 \\
\hline 8 & $\begin{array}{l}\text { Wheat straws } 55 \%+\text { Rapeseed stalks } 30 \% \\
+ \text { Corn cobs } 10 \%+\text { Dolomite } 5 \%\end{array}$ & 16.275 & 7.57 & 73.47 \\
\hline
\end{tabular}

Figure 4 presents the correlation between the inferior calorific value and ash content for all pellet samples. It can be noticed that the lowest calorific power is well correlated with the largest ash content (sample 3). We found a dicrepancy in sample 7, where we had an average calorific value of 15.847 $\mathrm{MJkg}^{-1}$ with an ash content of $10.35 \%$. The high ash content for sample 7 is caused by the addition of corn stalks. Figure 5 presents the volatile matter content in the case of the pellet samples obtained using wheat straws as the main biomass material. The lowest content is registered in the samples, where we added dolomite, a non-combustible material which does not volatize.

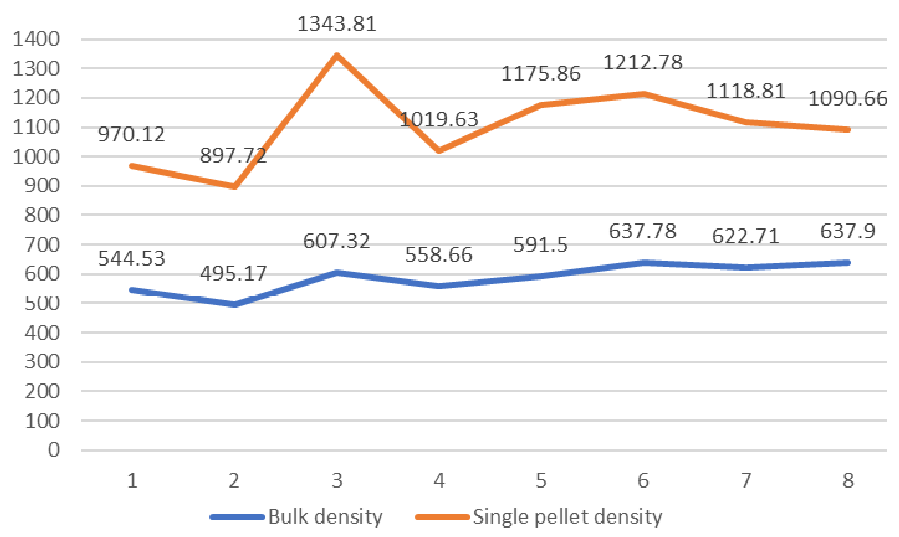

Fig. 3. Evolution of density for wheat straw pellets with and without additives

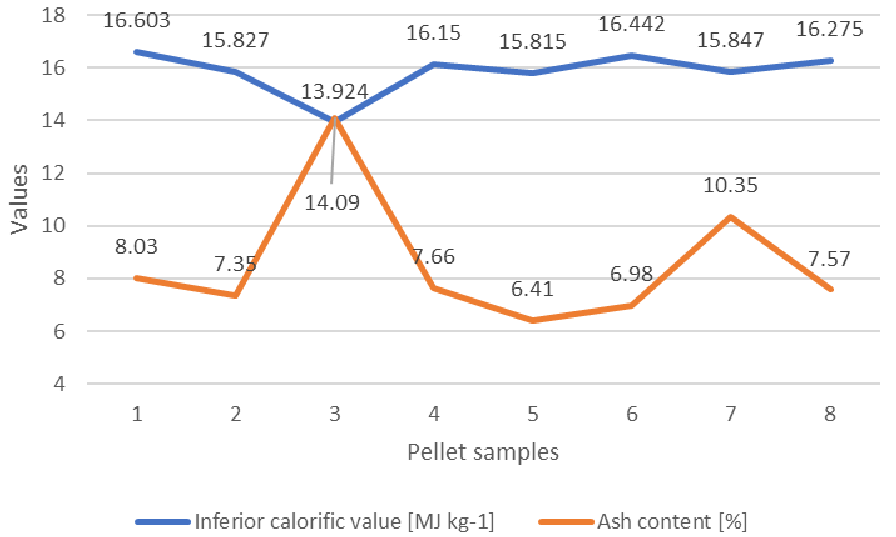

Fig. 4. Evolution and correlation between inferior calorific value and ash content 


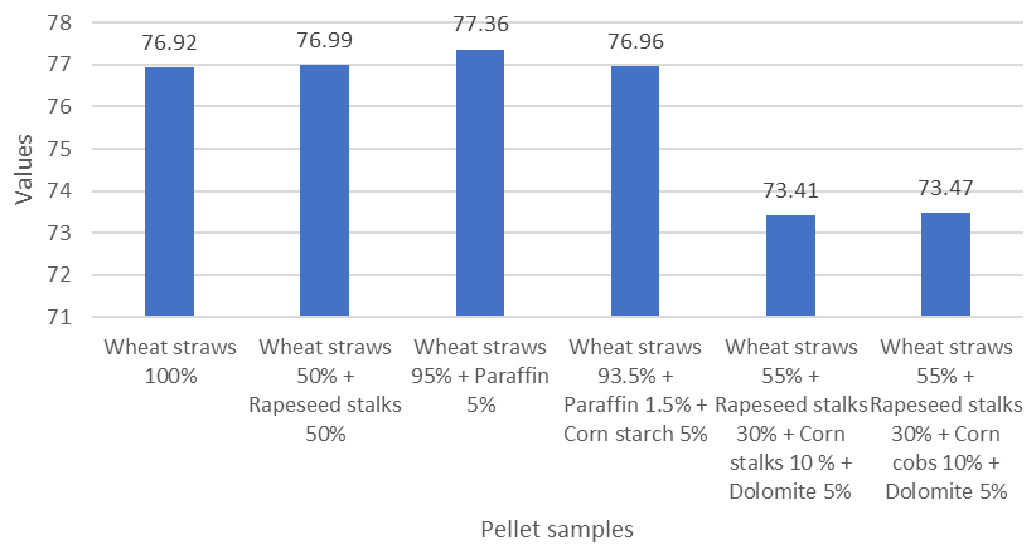

Fig. 5. Evolution of volatile matter content for wheat straw pellets with and without additives

The pellets obtained after combining different types of materials and those obtained by using additives showed good results, both during the production process as well as in terms of the quality parameters.

\section{Conclusions} drawn.

Based on the experimental results obtained testing the pellets, the following conclusions can be

1. The addition of paraffin, corn starch and dolomite, as well as the combination between the materials had a beneficial effect on the pellet length, surface and shape.

2. Moisture content of pellets registered values ranging between $8.25 \%$ and $11.65 \%$ for pellets obtained without using additives and between $7.48 \%$ and $9.25 \%$ for pellets obtained using additives, indicating that additives are beneficial for decreasing moisture and keeping it under $10 \%$, the desired value for optimal storage and use.

3. Bulk density and single pellet density registered significant increases for samples obtained using additives in the recipes.

4. Inferior calorific value registered a small decrease in the case of using parraffin and corn starch in wheat straw pellets, but that can be attributed to the fact that paraffin burns more slowly. Overall, the values indicate that pellets are suitable to be used as biofuels.

5. Ash content was also positively influenced by using additives, registering decreases in the ash contents for almost all samples obtained using additives (except sample 7, where the high ash content can be attributed to the the addition of corn stalks, which had a very high ash content in $100 \%$ corn stalk pellets).

6. Volatile matter content had little variations for pellets obtained using additives compared to those obtained without additives, except for pellets obtained with dolomite, which led to a 3-4 \% decrease.

The experimental researches showed that the use of additives has an overall beneficial effect on pellet recipes, mainly on their stability, storage characteristics and bulk density, but also gives a solution for using a series of biomass materials that did not show good pelleting attributes by themselves, making them suitable and ensuring their sustainable use.

\section{Acknowledgements}

This work was supported by a grant of the Romanian National Authority for Scientific Research and Innovation, CNCS/CCCDI -UEFISCDI, within PNCDI III, project number PN-III-P2-2.1-BG-2016-0266 - "Optimizing the composition of biomass mixtures for obtaining high quality pellets", ctr. 24 BG / 2016.

\section{References}

[1] Demirbas A. Progress and recent trends in biodiesel fuels, Energy Conversion and Management 50, 2009, pp. 14-34. 
[2] Găgeanu I., VoicuGh., Vladut V., Voicea I. Experimental research on the influence of recipes used on the quality of biomass pellets, Proceedings of 16th International Scientific Conference Engineering for Rural Development - Jelgava, 2017, pp. 785-791.

[3] Lu D., Tabil L., Wang D., Wang G. Manufacturing Wheat Straw Pellet with Wood Waste and Binders, CSBE/SCGAB 2013 Annual Conference, Univ. of Saskatchewan, Saskatoon, 7-10 July 2013.

[4] Jezerska L., Zajonca O., Rozbroja J., Vyletěleka J., Zegzulka J. Research on Effect of Spruce Sawdust with Added Starch on Flowability and Pelletization of the Material, IERI Procedia 8, 2014, pp. 154-163.

[5] Narra S., Tao Y., Glaser C., Gusovius H.J., Ay P. Increasing the Calorific Value of Rye Straw Pellets with Biogenous and Fossil Fuel Additives, Energy Fuels, 24, 2010, pp. 5228-5234: DOI:10.1021/ef100823b.

[6] Stahl M., Berghel J., Frodeson S., Granstrom K., Renstrom R. Effects on Pellet properties and energy use when starch is added in the wood-fuel pelletizing process, Energy Fuels Journal, vol. 26, no. 3, 2012, pp. 1937-1945.

[7] ISO 18134-1:2015 - Solid biofuels - Determination of moisture content - Oven dry method - Part 1: Total moisture - Reference method.

[8] ISO 17828:2015 - Solid biofuels - Determination of bulk density.

[9] CEN - EN 14918 - Solid biofuels - Determination of calorific value.

[10] ISO 18122:2015 - Solid biofuels - Determination of ash content.

[11] ISO 18123:2015 - Solid biofuels - Determination of the content of volatile matter. 